\title{
Preparation and Characterization of $\mathrm{LaMoO}_{3}, \mathrm{La}_{x} \mathrm{Sr}_{y} \mathrm{~V}_{z} \mathrm{O}_{3}$ and $\mathrm{La}_{x} \mathrm{Sr}_{y} \mathrm{Mo}_{z} \mathrm{O}_{3}$ Perovskite Type Oxides by the Sol-Gel Citrate Method
}

\author{
H.E. Figen*, N.O. Guldal And S.Z. BAYKara \\ Chemical Engineering Dept., Yildiz Technical University, Topkapi, Istanbul 34210, Turkey
}

\begin{abstract}
In this study, $\mathrm{LaMoO}_{3}, \mathrm{La}_{x} \mathrm{Sr}_{y} \mathrm{~V}_{z} \mathrm{O}_{3}$ and $\mathrm{La}_{x} \mathrm{Sr}_{y} \mathrm{Mo}_{z} \mathrm{O}_{3}$ perovskites have been prepared by the sol-gel citrate method and calcined at $1000^{\circ} \mathrm{C}$ for $5 \mathrm{~h}$. Ammonium carbonate and citric acid were used as complexing agent and solvent. Phases of synthesized materials were characterized with X-ray diffraction. Morphological analysis and elemental composition of perovskites were determined by scanning electron microscope and energy dispersive spectroscopy. The surface analyses of the solids have been studied using the Brunauer-Emmett-Teller surface analyzer. The effects of substitution of $x, y$, and $z$ on the physical properties of the synthesized perovskites were also investigated.
\end{abstract}

DOI: 10.12693 /APhysPolA.125.278

PACS: $81.20 . \mathrm{Fw}, 81.70 .-\mathrm{q}$

\section{Introduction}

Hydrogen production from hydrogen sulfide constitutes an alternative to the Claus process for treating hydrogen sulfide [1]. The process of thermal dissociation of hydrogen sulfide has potential for becoming an economic method for converting a hazardous waste into valuable products, conserve fossil fuels, and increase usable reserves of fossil fuels [2]. Direct decomposition of $\mathrm{H}_{2} \mathrm{~S}$ can be accomplished at high temperatures, usually above $700^{\circ} \mathrm{C}$, by means of catalysts, with the purpose of improving the reaction rates. At high temperatures, equilibrium gives favorable conversions [3]. The process is an endothermic one [4]:

$$
2 \mathrm{H}_{2} \mathrm{~S} \rightarrow 2 \mathrm{H}_{2}+\frac{1}{4} \mathrm{~S}_{8}, \quad \Delta H=79.5 \mathrm{~kJ} / \mathrm{mol} .
$$

Conventionally, composition of perovskites can be represented as $\mathrm{ABX}_{3}$, where $\mathrm{A}$ is a large cation, $\mathrm{B}$ is a transition metal and $\mathrm{X}$ is an anion. Since $\mathrm{X}$ is generally oxygen, the most common expression for perovskites is $\mathrm{ABO}_{3}$ [5].

Sol-gel method: A convenient method for preparation of composite materials, the sol-gel method is a solution process involving transition of a liquid "sol" system into a solid "gel" system. "Sol" is formed via suspension of a few hundred nm sized particles in the liquid phase. Upon submersion of solid macromolecules in the solvent, particles (gel) are condensed in the new phase. The precursors of the sol-gel method (acetates, nitrates, formiates, oxides hydroxides, amines) are expected to be reactive enough and to be easily soluble in the reaction medium [6].

Various studies have been carried out previously, pertaining to non-catalytic [7] and catalytic decomposition

\footnotetext{
*corresponding author; e-mail: hfigen@yildiz.edu.tr
}

of $\mathrm{H}_{2} \mathrm{~S}$, employing metal oxides [1] and metal sulfides $[3,4,8,9]$. Perovskites $\left(\mathrm{ABO}_{3}\right)$ catalysts are known to be more stable, and their activity can be improved depending on element B [10]. In the present work, perovskite catalysts containing Mo, V, and Sr have been synthesized by the sol-gel method and were characterized in terms of structural properties.

\section{Experimental}

\subsection{Preparation of perovskite oxides}

$\mathrm{LaMoO}_{3}, \mathrm{La}_{x} \mathrm{Sr}_{y} \mathrm{~V}_{z} \mathrm{O}_{3}$ and $\mathrm{La}_{x} \mathrm{Sr}_{y} \mathrm{Mo}_{z} \mathrm{O}_{3}$ perovskites (where $x, y$, and $z$ are 0.5 and 1 ) were prepared by the sol-gel citrate method. All precursors used in preparation of catalysts were hydrate nitrates and/or ammonium oxides of respective elements $\mathrm{La}\left(\mathrm{NO}_{3}\right)_{3} \cdot 6 \mathrm{H}_{2} \mathrm{O}$ (ABCR), $\left(\mathrm{NH}_{4}\right)_{6} \mathrm{Mo}_{7} \mathrm{O}_{24} \cdot 4 \mathrm{H}_{2} \mathrm{O}$ (Alfa Aesar), $\mathrm{NH}_{4} \mathrm{VO}_{3}$ (Alfa Aesar), $\mathrm{Sr}\left(\mathrm{NO}_{3}\right)_{2}$ (ABCR) because of their high solubility in water and homogeneity. Citric acid was used as a solgel agent and $1 \mathrm{M}\left(\mathrm{NH}_{4}\right)_{2} \mathrm{CO}_{3}$ was used to adjust $\mathrm{pH}$. After mixing the related nitrates in appropriate amounts with deionized water, citric acid was added to maintain the molar ratio 1.1. Then mixing of the solutions was followed by the addition of $1 \mathrm{M}\left(\mathrm{NH}_{4}\right)_{2} \mathrm{CO}_{3}$ to adjust the $\mathrm{pH}$ to 6 . The solutions were left to evaporate under $60^{\circ} \mathrm{C}$ to obtain sol-gel. The catalysts were then dried in an oven at $200^{\circ} \mathrm{C}$ under vacuum and the temperature was slowly increased to $230^{\circ} \mathrm{C}$. At this stage, a significant yellow/brown vapour output was observed. After releasing the citrate-nitrate-ammonium vapour, the precursor was milled and was calcinated at $1000{ }^{\circ} \mathrm{C}$ for $5 \mathrm{~h}$ under static air using a heating rate of $5{ }^{\circ} \mathrm{C} / \mathrm{min}$.

\subsection{Characterization}

Instrumental analysis with X-ray diffraction (XRD), scanning electron microscopy-energy dispersive spectroscopy (SEM-EDS) and the Brunauer-Emmett-Teller 
(BET) techniques were used for structural study of the samples. Characterization of crystal structure and determination of crystallographic parameters of the perovskite catalysts were performed by XRD analyses. Samples were ground in an agate mortar and settled in an aluminum sample holder. X-ray diffraction analyses were carried out at ambient temperature using a Philips Panalytical X'Pert-Pro diffractometer in a diffraction angle range of $10^{\circ}$ to $90^{\circ}$ with $\mathrm{Cu} K_{\alpha}$ radiation $(\lambda=$ $0.15418 \mathrm{~nm}$ ) at operating parameters of $40 \mathrm{~mA}$ and $45 \mathrm{kV}$ with a step size of $0.02^{\circ}$ and speed of $1^{\circ} / \mathrm{min}$. Phase identification of samples were performed by powder diffraction file (PDF) database which is available in X'Pert High Score Plus in Pan Analytical XRD equipment. Specific surface area of the catalysts were characterized by using BET technique under $\mathrm{N}_{2}$ adsorptive gas and $\mathrm{He}$ carrier gas at $77 \mathrm{~K}$ after outgassing at $0.6 \mathrm{~Pa}$ and $473 \mathrm{~K}$, using Quantachrome, Autosorb Automated Gas Sorption System BET Instrument. Microstructure and surface morphology of the catalysts were observed by field-emission gun scanning electron microscopy (CamScan Apollo 300 FEG-SEM equipment) and semi-quantitative elemental analyses were carried out with X-ray energy dispersive spectroscopy (Oxford EDS apparatus).

\section{Results and discussion}

XRD patterns of prepared perovskite type oxides are given in Fig. 1 and crystalline phase parameters are listed in Table I.

It is observed that the elements at B-sites (molybdenum, strontium and vanadium) and their percentage have an effect on forming different types of crystalline structure. The XRD pattern of the sample P-1 ( $\left.\mathrm{La}\left(\mathrm{Sr}_{0.5} \mathrm{Mo}_{0.5}\right) \mathrm{O}_{3}\right)$ contains different crystalline phases $\left(\mathrm{La}_{2} \mathrm{Mo}_{3} \mathrm{O}_{12}, \mathrm{SrMoO}_{4}\right.$, and $\left.\mathrm{MoO}_{3}\right)$; sample P-2 $\left(\mathrm{LaSr}_{0.5} \mathrm{~V}_{0.5} \mathrm{O}_{3}\right)$ has also three different crystalline phases $\left(\mathrm{Sr}_{3}\left(\mathrm{VO}_{4}\right)_{2}, \mathrm{La}_{2} \mathrm{O}_{3}\right.$, and $\left.\mathrm{La}_{13} \mathrm{SrV}_{4} \mathrm{O}_{31}\right)$. $\mathrm{La}_{0.5} \mathrm{Sr}_{0.5} \mathrm{MoO}_{3}$ catalyst, coded $\mathrm{P}-3$, has four crystalline structures $\left(\mathrm{SrMoO}_{4}, \mathrm{La}_{4} \mathrm{O}_{9} \mathrm{Sr}_{3}, \mathrm{La}_{2} \mathrm{MoO}_{6}, \mathrm{MoO}_{3}\right)$, sample $\mathrm{P}-4\left(\mathrm{La}_{0.5} \mathrm{Sr}_{0.5} \mathrm{VO}_{3}\right)$ has three phases $\left(\mathrm{LaVO}_{4}\right.$, $\left.\mathrm{La}_{0.5} \mathrm{Sr}_{0.5} \mathrm{VO}_{2.95}\right)$ and sample P-5 $\left(\mathrm{LaMoO}_{3}\right)$ has only one crystalline structure $\left(\mathrm{La}_{2} \mathrm{Mo}_{3} \mathrm{O}_{12}\right)$, depending on having only Mo element at B-site. The XRD patterns of the perovskite catalysts are displayed in Fig. 1a1-a5.

The microstructures of prepared catalysts were determined using a SEM. The samples were fixed to the sample holder with carbon sticky band. Figure 1b1-b5 shows SEM micrographs at $10000 \times$ magnification (for P-1), and $25000 \times$ magnification (for P-2, P-3, P-4, P-5) obtained by backscattered electron detector.

According to semiquantitative elemental X-ray analysis (EDS) results, the atomic ratios of $\mathrm{A}_{1} \mathrm{~A}_{2} / \mathrm{B}_{1} \mathrm{~B}_{2}$ sites are also given in Table II. Except for sample P-1 $\left(\mathrm{La}\left(\mathrm{Sr}_{0.5} \mathrm{Mo}_{0.5}\right) \mathrm{O}_{3}\right)$, these results indicated that the theoretical preparation ratios of perovskites are compatible with the EDS results. Since surface inspection is possible with the EDS technique, molybdenum content, which has

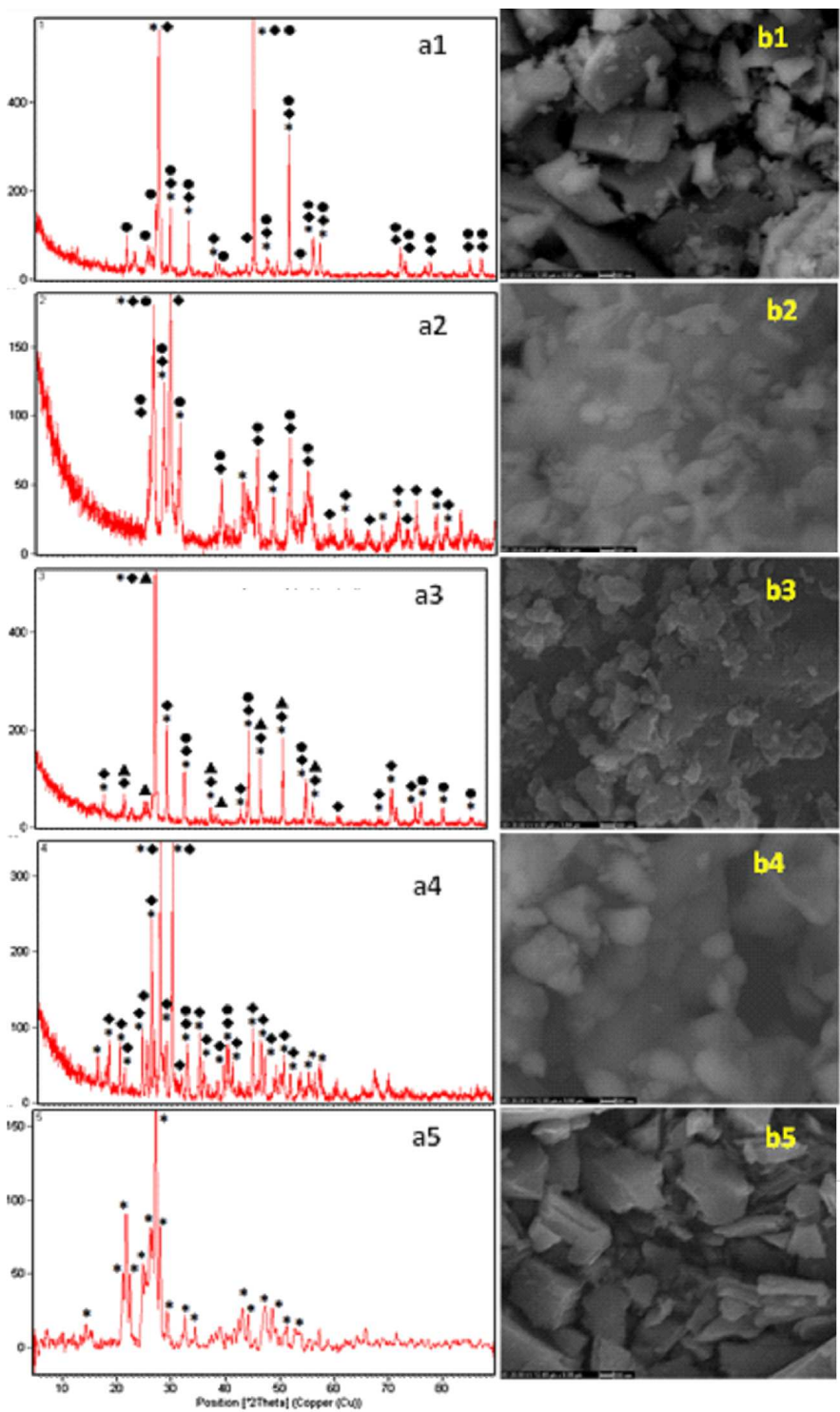

Fig. 1. XRD spectra (a1)-(a5) and SEM micrographs (b1)-(b5) of perovskite oxide catalysts (P1-P5).

a tendency of rising to the surface, appears to be higher (0.98) than the expected value $(0.5)$ in sample P1.

\section{Conclusion}

$\mathrm{LaMoO}_{3}, \mathrm{La}_{x} \mathrm{Sr}_{y} \mathrm{~V}_{z} \mathrm{O}_{3}$ and $\mathrm{La}_{x} \mathrm{Sr}_{y} \mathrm{Mo}_{z} \mathrm{O}_{3}$ perovskite-type catalysts with different compositions have been synthesized by the sol-gel citrate method employing $\mathrm{La}\left(\mathrm{NO}_{3}\right)_{3} \cdot 6 \mathrm{H}_{2} \mathrm{O}, \quad \mathrm{Sr}\left(\mathrm{NO}_{3}\right)_{2}, \quad \mathrm{NH}_{4} \mathrm{VO}_{3}$, $\left(\mathrm{NH}_{4}\right)_{6} \mathrm{Mo}_{7} \mathrm{O}_{24} \cdot 4 \mathrm{H}_{2} \mathrm{O}$, citric acid monohydrate and ammonium carbonate were used as reagents. The decomposition of the precursor complex was carried out at $100{ }^{\circ} \mathrm{C}$ for $5 \mathrm{~h}$ under static air in order to synthesize the perovskite structures as confirmed by XRD. According to SEM results, the perovskites contained both large $(2 \mu \mathrm{m} \times 5 \mu \mathrm{m})$ and small $(250 \mathrm{~nm} \times 250 \mathrm{~nm})$ sized 
particles. These results confirmed that Mo substitution in sample $\mathrm{P} 1$ and $\mathrm{P} 3$, and $\mathrm{V}$ substitution in sample $\mathrm{P} 2$ and $\mathrm{P} 4$ have resulted in more homogeneous particle distribution, and reduction in surface area. In view of the results obtained, it can be concluded that the sol-gel process is quite satisfactory as a method for the perovskite type catalyst preparation.

Crystalline phase properties of catalysts samples.

TABLE I

\begin{tabular}{c|c|c|c|c}
\hline \hline & Catalyst & Phases & Reference code & Crystal system \\
\hline \multirow{3}{*}{ P1 } & $\mathrm{LaSr}_{0.5} \mathrm{Mo}_{0.5} \mathrm{O}_{3}$ & $\mathrm{La}_{2} \mathrm{Mo}_{3} \mathrm{O}_{12}$ & $00-045-0407$ & tetragonal \\
& & $\mathrm{SrMoO}_{4}$ & $00-008-0482$ & tetragonal \\
& & $\mathrm{MoO}_{3}$ & $03-065-2421$ & orthorhombic \\
\hline \multirow{3}{*}{ P2 } & \multirow{2}{*}{$\mathrm{LaSr}_{0.5} \mathrm{~V}_{0.5} \mathrm{O}_{3}$} & $\mathrm{Sr}_{3}\left(\mathrm{VO}_{4}\right)_{2}$ & $01-081-1844$ & rhombohedral \\
& & $\mathrm{La}_{2} \mathrm{O}_{3}$ & $01-074-1144$ & hexagonal \\
& & $\mathrm{La}_{13} \mathrm{SrV}_{4} \mathrm{O}_{31}$ & $00-038-0087$ & hexagonal \\
\hline \multirow{3}{*}{ P3 } & $\mathrm{SrMoO}_{0.5} \mathrm{Sr}_{0.5} \mathrm{MoO}_{3}$ & $\mathrm{La}_{4} \mathrm{O}_{9} \mathrm{Sr}_{3}$ & $00-008-0482$ & tetragonal \\
& & $\mathrm{La}_{2} \mathrm{MoO}_{6}$ & $01-072-0893$ & monoclinic \\
& & $\mathrm{MoO}_{3}$ & $00-074-0182$ & tetragonal \\
& & $\mathrm{LaVO}_{4}$ & $00-023-0324$ & monoclinic anorthic \\
P4 & \multirow{2}{*}{$\mathrm{La}_{0.5} \mathrm{Sr}_{0.5} \mathrm{VO}_{3}$} & $\mathrm{Sr}_{2} \mathrm{~V}_{2} \mathrm{O}_{7}$ & $01-072-2137$ & cubic \\
& & $\mathrm{La}_{0.5} \mathrm{Sr}_{0.5} \mathrm{VO}_{2.95}$ & $00-033-1343$ & cubic \\
\hline P5 & $\mathrm{LaMoO}_{3}$ & $\mathrm{La}_{2} \mathrm{Mo}_{3} \mathrm{O}_{12}$ & $01-070-1382$ & monoclinic
\end{tabular}

TABLE II

Particle distribution, surface area and atomic ratio measurements of perovskite catalysts.

\begin{tabular}{c|c|c|c|c}
\hline \hline & $\begin{array}{c}\text { Theoretical } \\
\text { atomic ratio }\end{array}$ & $\begin{array}{c}\text { EDS } \\
\text { atomic ratio }\end{array}$ & $\begin{array}{c}\text { BET area } \\
{\left[\mathrm{m}^{2} / \mathrm{g}\right]}\end{array}$ & $\begin{array}{c}\text { Particle distribution } \\
\text { (according to SEM micrographs) }\end{array}$ \\
\hline P1 & $1.00-0.5-0.5$ & $0.74-0.27-0.98$ & 2.026 & $600 \mathrm{~nm} \times 1 \mu \mathrm{m}-2 \mu \mathrm{m} \times 5 \mu \mathrm{m}$ \\
P2 & $1.00-0.5-0.5$ & $0.92-0.49-0.59$ & 7.556 & $300 \mathrm{~nm} \times 1 \mu \mathrm{m}-1.5 \mu \mathrm{m} \times 1.5 \mu \mathrm{m}$ \\
P3 & $0.5-0.5-1.00$ & $0.56-0.41-1.03$ & 0.823 & $250 \mathrm{~nm} \times 250 \mathrm{~nm}-800 \mathrm{~nm} \times 1.2 \mu \mathrm{m}$ \\
P4 & $0.5-0.5-1.00$ & $0.35-0.57-1.08$ & 0.527 & $500 \mathrm{~nm} \times 500 \mathrm{~nm}-1.2 \mu \mathrm{m} \times 1.5 \mu \mathrm{m}$ \\
P5 & $1.00-1.00$ & $0.84-1.15$ & 0.489 & $500 \mathrm{~nm} \times 1.5 \mu \mathrm{m}-2 \mu \mathrm{m} \times 2.2 \mu \mathrm{m}$
\end{tabular}

\section{Acknowledgments}

This study is supported by the Black Sea ERA.NET 2010 Pilot Joint Call (project No. BS-ERA.Net: 028) acronymed as H2S-PROTON and TÜBİTAK-MAG (project No. 111 M801-Hydrogen production from $\mathrm{H}_{2} \mathrm{~S}$ decomposition in micro-structured proton-conducting solid oxide membrane reactors).

\section{References}

[1] O.A. Salman, A. Bishara, A. Marafi, Energy 12, 1227 (1987).

[2] W.S. Harvey, J.H. Davidson, E.A. Fletcher, Ind. Eng. Res. 37, 2323 (1998).

[3] V.E. Kaloidas, N.G. Papayannakos, Int. J. Hydrogen Energy 12, 403 (1987).
[4] T. Chivers, C. Lau, Int. J. Hydrogen Energy 12, 561 (1987).

[5] L.G. Tejuca, J.S. Fierro, J.M.D. Tascon, Adv. Catal. 36, 237 (1989).

[6] A.C. Pierre, Introduction to Sol-Gel Processing, Kluwer Academic Publishers, Boston 1998.

[7] A.A. Adesina, V. Meeyoo, G. Foulds, Int. J. Hydrogen Energy 20, 777 (1995).

[8] L.M. Alshamma, S.A. Naman, Int. J. Hydrogen Energy 15, 1 (1990).

[9] K. Fukuda, M. Dokiya, T. Kameyama, Y. Kotera, Ind. Eng. Chem. Fundamen. 17, 243 (1978).

[10] H. Tanaka, M. Misono, Curr. Opin. Solid State M. 5, 381 (2001). 